\title{
Primary Abdominal Pregnancy With Haemoperitoneum: An Extremely Rare Case Successfully Managed during COVID 19 Pandemic
}

\section{Rajshree Dayanand Katke*}

Professor and Unit Chief, Department of Obstetrics and Gynaecology, Grant Government Medical College and Sir J.J. Group of Hospitals, Mumbai, India

Correspondence to: Rajshree Dayanand Katke, Professor and Unit Chief, Department of Obstetrics and Gynaecology, Grant Government Medical College and Sir J.J. Group of Hospitals,Mumbai, India; E-mail: drrajshrikatke@gmail.com

Received date: September 07, 2021; Accepted date: September 21, 2021; Published date: September 28, 2021

Citation: Katke RD (2021) Primary Abdominal Pregnancy With Haemoperitoneum: An Extremely Rare Case Successfully Managed during COVID 19 Pandemic. J Obst Gynecol Surg 2(2): pp. 1-3. doi: 10.52916/jogs214016

Copyright: (C2021 Katke RD. This is an open-access article distributed under the terms of the Creative Commons Attribution License, which permits unrestricted use, distribution and reproduction in any medium, provided the original author and source are credited.

\section{ABSTRACT}

The abdominal pregnancy is a very rare type of ectopic pregnancy. This can be a primary abdominal ectopic or a secondary abdominal following rupture of tubal or corneal ectopic. this case is reported for its rarity and the challenging surgery required for its management as described below for a successful maternal outcome.

\section{Keywords:}

Primary abdominal pregnancy, Ectopic, Rare, COVID-19, Pandemic.

\section{Introduction}

Abdominal ectopic can be viewed as a form of an ectopic pregnancy where the embryo or fetus is evolving outside the uterus in the abdomen/peritoneal cavity but not in the Fallopian tube, ovary or broad ligament [1-3].

As per Indian Council of Medical Research task Force the occurrence of ectopic pregnancy in India is 3.86 per 1000 live births amongst all hospital reported pregnancies. Of these $95 \%$ are tubal [4] and 1-4\% are abdominal [5]. Abdominal pregnancy typically ensues following tubal abortion or tubal rupture.

\section{Case Report}

28 year old, married since 7 years, gravida four, parity three, living three, with 4 months gestation, came with c/o pain abdomen since 2 days and was referred from Shahpur with ultrasound suggestive of extra uterine fetal demise of gestation age of 14.5 weeks seen in peritoneal cavity and ectopic placenta and bulky uterus with ascites. with an estimated fetal weight of $114 \mathrm{~g}$. Patient was referred as a case of extra uterine fetal demise with severe anemia ( Hemoglobin $4 \mathrm{gm} \%$ ).

Obstetric History: gravida four, parity three, living three, with 4 months gestation,

All previous three female children are born by normal vaginal delivery.

On Examination, the patient was afebrile, had severe pallor +++ , (Hemoglobin $4 \mathrm{gm} \%$ ), no icterus/edema.

Her pulse was $100 / \mathrm{min}$, blood pressure was $120 / 80 \mathrm{~mm}$ Hg SpO2: $98 \%$ on Room Air. Her systemic examination, both cardiovascular and respiratory were within normal limits.

Her per abdomen examination revealed, on inspection, distension of abdomen, more on the lower side, with a suprapubic bulge. On palpation, minimal Tenderness over the abdomen present, superficial fetal part like structure felt at the level of umbilicus. No evidence of free fluid demonstrated clinically. On per speculum examination, cervix congested.

On per vaginum examination, uterus could not be felt separately, exact size of the uterus could not be estimated, minimal tenderness in fornices present.

In view on ongoing pandemic, COVID 19 Rapid Antigen Test and RTPCR were sent and were Negative.

Investigations revealed hemoglobin: $4.9 \mathrm{G} \%$, Total Leucocytes Counts $10500 \mathrm{cc} \mathrm{mm}$ and platelets being 118000 .

Ultra sound abdomen: findings suggestive of ectopic abdominal pregnancy corresponding to 15 weeks with a heterogeneously hypoechoic mass of $6 \times 9 \times 7 \mathrm{~cm}$, noted in right adnexa showing vascularity on colour doppler, most likely placenta with implantation in the peritoneal cavity.,. findings suggestive of fetal demise. uterus bulky minimal free fluid noted in pelvis.

Beta HCG :I 40, $000 \mathrm{mIU} / \mathrm{mL}$

2 pints Whole Blood transfused.

The patient was planned for Emergency Exploratory Laparotomy With Abdominal Ectopic Excision.

Intra operative infra umbilical medial vertical incision taken over lower abdomen and abdomen opened in layers till parietal peritoneum.

parietal peritoneum had bluish discoloration.the peritoneum was stretched and distended. the parietal peritoneum opened, followed by a gush of blood, hemoperitoneum of around $500 \mathrm{cc}$ was present. blood clots measuring around $350-400 \mathrm{cc}$ removed.

Placenta and demised baby ( of 15 weeks gestation) was seen in the abdominal cavity with the intact umbilical cord connecting the fetus and placenta seen. The demised fetus weighing about $30 \mathrm{~g}$ with placenta of $220 \mathrm{~g}$ was seen in amniotic sac.

Uterus was bulky, approximately 6 weeks gestation size, soft in consistency, congested. Both the fallopian tubes and ovaries and adnexa were intact and normal. there was no utero peritoneal fistula. The bowel and omentum were adhered to the sac and the demised fetus along with the placenta was separated meticulously from the surrounding viscera and was sent for histopathological sampling.The hemoperitoneum was involving the peri - hepatic and peri-splenic regions,the right ruptured cornual end was bleeding and was close to the infundibulopelvic and the ovarian ligament. Also, the placenta was in its close proximity. The bleeders were present over the posterior surface of uterus which were closed with 2 intermittent 
Citation: Katke RD (2021) Primary Abdominal Pregnancy With Haemoperitoneum: An Extremely Rare Case Successfully Managed during COVID 19 Pandemic. J Obst Gynecol Surg 2(2): pp. 1-3. doi: 10.52916/jogs214016

hemostatic sutures (Figure 1-4).
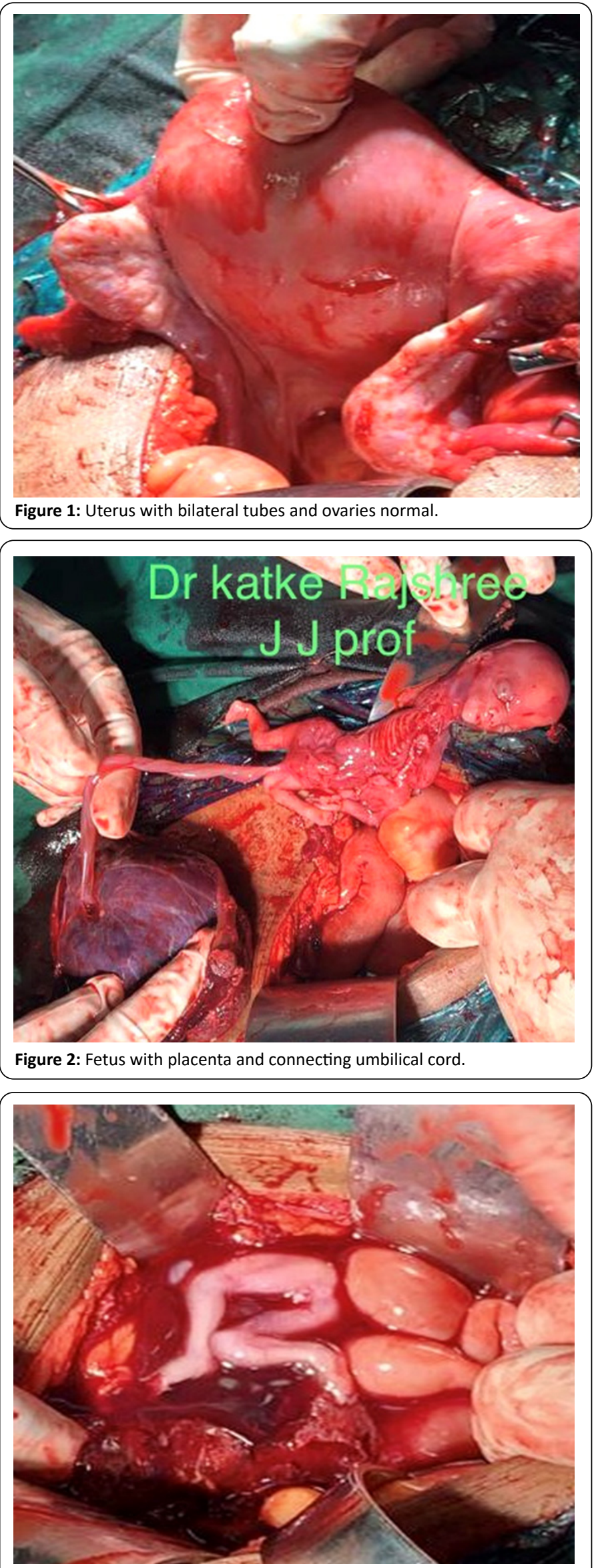

Figure 3: Fetal legs with hemoperitoenum and bowel seen.

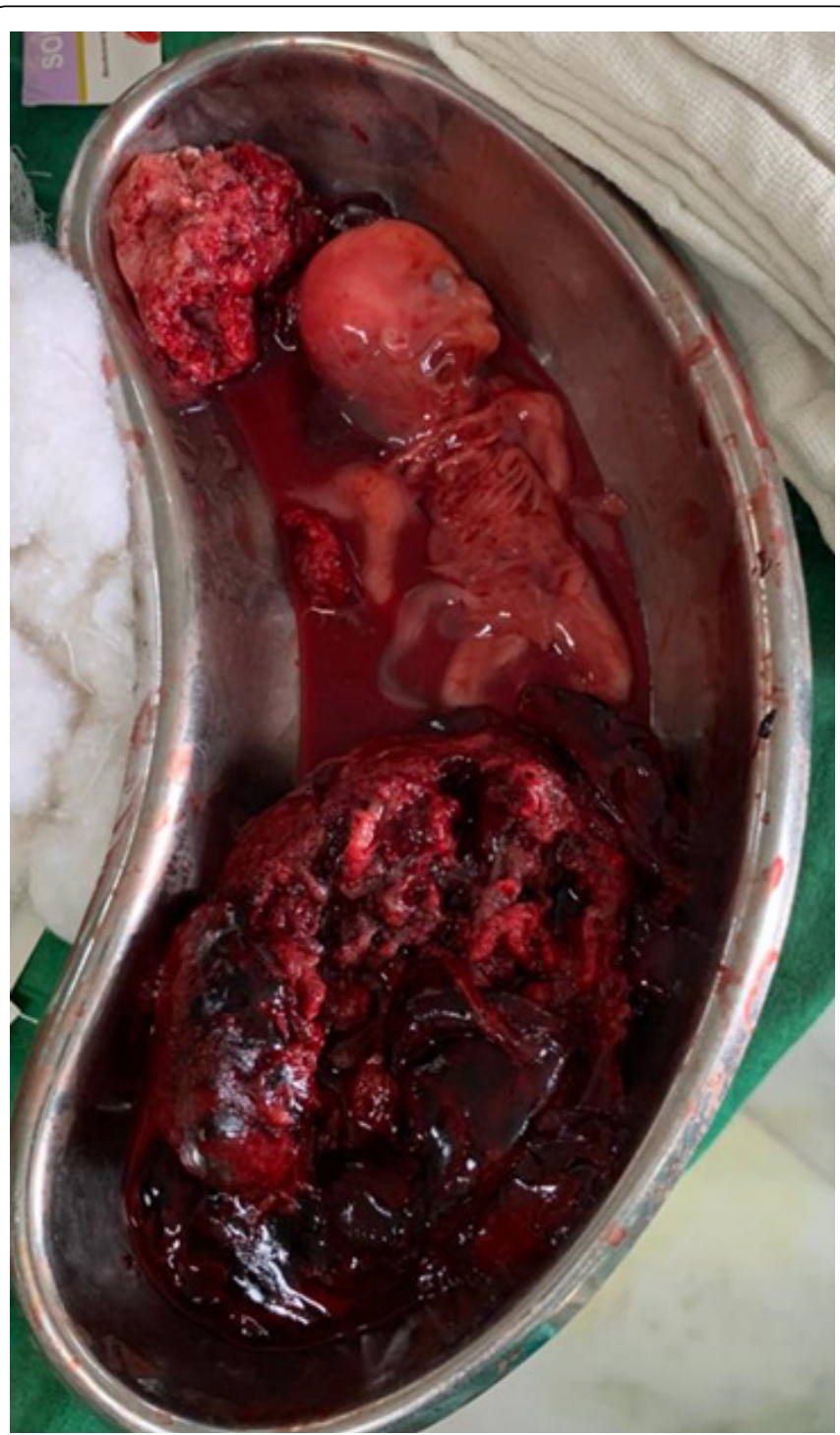

Figure 4: Specimen demonstrating fetus with placenta and umbilical cord.

The patient was transfused with two pints of whole blood post operatively.

The patient was monitored in critical care unit, her post operative period was uneventful and she was later discharged after suture removal with healthy scar.

The histopathology report was suggestive of fetus, products of conception and placenta having no specific pathology.

\section{Discussion}

In 1942, Studdiford defined the criteria for abdominal pregnancy:

1. normal bilateral fallopian tubes and ovaries,

2. absence of uteroperitoneal fistula, and

3. presence of a pregnancy related to the peritoneal surface exclusively

Of all pregnancies extra uterine are Approximately $1 \%$ of and $1-3 \%$ of these are peritoneal implantations [6]. The maternal mortality rate is 0.5 to $18 \%$ and perinatal mortality rate ranges between $40 \%$ to $95 \%$ [7]. if the condition is not diagnosed and managed timely, then The maternal mortality and morbidity rates are very high. Advanced abdominal pregnancy is defined as pregnancy which is past 20 weeks of gestation and is associated 
with high foetal and maternal morbidity and mortality. A very few live birth rates have been reported.

Fedele et al found ultrasonography to be beneficial in the early diagnosis however it is not useful in advanced gestation [8].

$M R I$ is also equally useful to diagnose abdominal pregnancy [9]. The amount of placental invasion, its association to the abdominal and pelvic organs and the vascular supply especially the placental blood supply, could be more closely visualised by magnetic resonance imaging [10].

Abdominal pregnancies should be terminated at the time of diagnosis, as the possibility for delivering of a healthy live infant is less and the risk of maternal complications is indeed high. However,expectant management to attain foetal maturity has been tried and has been effective in merely rare cases [11].

It is implied for obstetrician to borne the likelihood of abdominal pregnancy in cases of rudimentary horn along with pain in abdomen. It remains a diagnostic and therapeutic challenge when such patients present as acute abdomen in emergency. Diagnostic challenge is still a matter of fact in developing countries that are treated with Timely laparotomy in haemodynamically unstable patients [12].

Such cases could be positively managed with opportune precise diagnosis, decent clinical judgement vital surgical intervention, and excellent surgical expertise [13].

Knowledge about the site of tubal pregnancy may guide the clinician concerning the nature of the outcome of the ectopic pregnancy. Virtuous clinical verdict along with the obtainability of rapid ultrasound facilities helps in early treatment and reducing complications [14].

\section{Conclusion}

The incidence of primary abdominal ectopic is extremely rare and it requires a clinical acumen and judgement for early diagnosis and timely management with great surgical expertise to reduce the complications.

\section{Conflict of Interest}

The author declares that they have no conflict of interest regarding the publication of this case report.

Funding: No funding from an external source supported the publication of this case report.

Patient Consent: Obtained.

\section{References}

1. Nkusu Nunyalulendho D, Einterz EM (2008) Advanced abdominal pregnancy: case report and review of 163 cases reported since 1946. Rural Remote Health 8(4): pp. 1087.

2. Agarwal N, Odejinmi F (2014) Early abdominal ectopic pregnancy: Challenges, update and review of current management. The Obstetrician and gynaecologist16(3): pp. 193-198.

3. Masukume G (2014) Insights into abdominal pregnancy. Wikiversity J Med 1 (2): pp. 1-6.

4. Cunningham FG, Gant NF, Leveno KJ et al. (Eds). (2001) Williams Obstetrics 21st edn. New York, McGraw Hill: p. 899.

5. Shaw HA, Ezenwa E (2000) Secondary abdominal pregnancy in a Jehovah's Witness. South Med J 93: pp. 898-900.

6. Parekh VK, Bhatt S,Dogra VS (2008) Abdominal pregnancy: An unusual presentation. JUM 27(4): pp. 679-681.

7. Strafford JC, Ragan WD (1977) Abdominal pregnancy Review of current management. Obstet Gynecol 50(5): pp. 548-552.

8. Fedele L, Dorta M, Vercellini P, et al. (1988) Ultrasound in the diagnosis of subclasses of unicornuate uterus. Obstet Gynaecol 71(2): pp. 274-277.

9. Dahiya K, Sharma D (2007) Advanced abdominal pregnancy; A diagnostic and management dilemma. J Gynecol Surg 23(2): pp. 69-72.

10. OzerenS, CaliskanE,CorakciA, etal.(2004)Magneticresonance imagingand angiography for the prerupture diagnosis of rudimentary uterine horn pregnancy. Acta Radiol 45: pp. 878-881.

11. Beddock R, Naepels P, Gondry C, et al. (2004) Diagnosis and current concepts of management of advanced abdominal pregnancy. Gynecol Obstet Fertil 32(1): pp. 32:55.

12. Katke RD, Raina J (2013) Secondary abdominal pregnancy following rupture of bicornuate uterus in early third trimester: a case report and review of literature. Int J Reprod Contracept Obstet Gynecol 2: pp. 454-457.

13. Sood A, Katke RD (2013) Live secondary abdominal pregnancy- by chance!! Int J Reprod Contracept Obstet Gynecol 2: pp. 251-253.

14. Katke RD, Shaikh A (2015) Prediction of outcome of tubal ectopic pregnancy on the basis of site of implantation of embryo in the fallopian tube. Int J Reprod Contracept Obstet Gynecol 4: pp. 1431-1435. 